\title{
LÉXICO DE LOS CHICLEROS EN CHETUMAL
}

Aunque en la actualidad la dialectología recoge descripciones sincrónicas, debe recordarse que inicialmente el análisis dialectal no se emprendió por sí mismo, sino que los intereses por la distribución geográfica de los fenómenos lingüísticos se derivaron con frecuencia de cuestiones diacrónicas sobre origen, difusión y pérdida de segmentos lingüísticos y que, durante algún tiempo, el cambio lingüístico y las variedades geográficas y sociales de la lengua se estudiaron como disciplinas separadas: la lingüística histórica y la dialectología.

La concentración de la dialectología tradicional sobre dialectos rurales llevó a negar las restantes variedades. Este camino no fue sino una primera estrategia metodológica que mostraba más interés por el descubrimiento de restos de latín vulgar que por la variación dialectal misma. Sin embargo, ese camino también mostró la complejidad y variedad de los fenómenos lingüísticos, pues al interior del dialecto y del habla local se comenzaron a notar variedades individuales en función de la edad, la clase social, el sexo, la profesión u oficio, etc. Precisamente, desde la última característica de esta perspectiva -el oficio- parto para realizar el estudio del vocabulario que utilizan los chicleros, hombres solitarios que trabajan en el monte.

En la recopilación de los materiales lingüísticos utilicé el método conocido como palabras y cosas. Es así que, mediante la formulación de pregunta indirecta, obtuve una lista de formas -que sobrepasa las cien denominaciones-que me ha permitido conocer la idiosincrasia, costumbres y peculiaridades del grupo social que forman los chicleros de Chetumal.

Por otro lado, sin ser el objetivo principal determinar la etimología de cada una de las voces usadas -sean éstas indígenas 
o no- en la actividad chiclera, su conocimiento puede ser útil para investigar el origen o la procedencia de los objetos que designan y, en consecuencia, las influencias de unas culturas y pueblos en otros. Así es que, con el empleo del método palabras y cosas logré obtener datos lingüísticos y etnográficos de utilidad para conocer mejor la ideología de estos hombres, al mismo tiempo que el análisis de los elementos léxicos recogidos ha permitido adentrarme en esta pequeña parcela del español mexicano.

Apoyado amablemente por los chicleros y excavando en sus recuerdos, estos hombres convirtieron mi escaso cuestionario en una guía de extensión considerable. Dicha lista fue modificándose - a veces en cada entrevista surgían nuevas denominaciones- hasta formar una unidad homogénea que cubre todas las actividades del rudo trabajo en el monte. La coherencia de esta guía de cuestiones se basa en que está estructurada en varios campos semánticos que permiten conjuntar palabras -que se relacionan semánticamente y que se organizan en torno a un concepto base-de manera ordenada y sistemática.

Los cuestionarios fueron aplicados durante 1996 a varios chicleros - algunos ya retirados- en Chetumal, Felipe Carrillo Puerto y Noh Bec ${ }^{1}$. Durante la aplicación del cuestionario, recurrí al uso de láminas y materiales fotocopiados y a la pregunta indirecta con el objeto de no sugerir respuesta alguna. Por esta misma causa, traté de amoldarme a las características del habla de los entrevistados; así, si obtenía paila, las preguntas relacionadas con ésta: 'recipiente para cocinar el chicle', las hacía usando la forma dicha por el chiclero: ¿En qué asientan la paila? Pienso que al eliminar diferencias lingüísticas, el informante se hace consciente de que sus respuestas son útiles y esto hace que la encuesta siga su curso natural. De igual modo he procurado hacer las preguntas de una manera clara y sencilla evitando términos cultos, abstractos, y tecnicismos que hubieran podido llevarme a errar el camino.

Este trabajo no pretende tener carácter contrastivo pues los estudios puramente lingüísticos sobre el léxico de la chiclería no existen. He consultado, sin embargo, investigaciones de carácter antropológico que me han ayudado en la elaboración

${ }^{1}$ Los informantes (2) fueron entrevistados en estos dos últimos lugares pues allá residen en la actualidad, sin embargo habían trabajado durante muchos años en la central de Chetumal, de ahí su inclusión. 
del cuestionario y como punto de partida para el conocimiento del oficio, pero no para llegar a establecer la extensión real de cada palabra. El contraste que pueda observarse en las voces obtenidas en Chetumal solamente tendría carácter parcial frente a las denominaciones campechanas documentadas en el amplio trabajo de Martha Ponce 2 .

Antes de presentar los resultados de las encuestas, proporciono una narración que intenta mostrar las jornadas de trabajo, los problemas, las características del campamento y toda la actividad de los chicleros. Tal vez carezca de uniformidad, ya que es un relato surgido de las conversaciones con los informantes, quienes vivieron distintas situaciones en épocas diferentes - de ahí el uso del copretérito en esta recreación.

En la exposición de los resultados documento primero la denominación obtenida en Chetumal, a veces completándola o contrastándola con lo dicho por Ponce, Juventino Poot ${ }^{3}$ y los diversos diccionarios consultados.

La etimología de las palabras no hispánicas la proporciono cuando he encontrado su referencia íntegra o parcial en los diversos lexicones y cuando su uso - sobre todo- ha sido amplio en la comunidad de chicleros, uso que evidenciaría el préstamo momentáneo de ciertos indigenismos en esta lengua especializada, por un lado, y su posible traslado a la lengua común de la región -ya que algunos de ellos los he podido documentar en conversaciones cotidianas al margen de los trabajos de chiclería- como préstamos establecidos, por el otro. No hago lo mismo con las castellanas, pues en el Diccionario de la Real Academia Española (DRAE) y en el Diccionario crítico-etimológico castellano e hispánico de Corominas y Pascual (DCECH) pueden hallarse las notas sobre significados, etimologías y cambios semánticos de las palabras.

Las observaciones que resultaron del análisis de las voces documentadas las presento bajo el título de conclusiones. Finalmente, en apéndices ofrezco tanto el cuestionario como los nombres de los informantes a quienes fue aplicado y un índice general que contiene todas las palabras registradas con un número para facilitar su consulta en el cuerpo de la exposición.

${ }^{2}$ La montaña chiclera: vida cotidiana y trabajo, Centro de Investigaciones y Estudios Superiores en Antropología Social, México, 1990.

${ }^{3}$ El chicle y los mayas de Quintana Roo, SEP-INI, México, 1982. 
JoRnADA DE LOS CHICLEROS. ENGANCHE, MONTEO Y HATO

Al llegar la época de lluvias a Quintana Roo, comenzaba la temporada del chicle. Los capataces andaban en busca de chicleros para engancharlos. Cuando lo conseguían (cosa que no era rara, pues la temporada del corte de caoba ya había concluido y los hombres no tenían trabajo) les daban un anticipo, el administrador les abría una cuenta en la bodega de la central para adquirir víveres para su familia y les entregaba el quincenal para cubrir sus gastos más urgentes antes de irse a la montaña. Cuando el chiclero era soltero, sólo se abastecía en la bodega del campamento.

Las bodegas se hallaban en las centrales de la ribera del Río Hondo; en ellas, aparte de los víveres, se concentraba el chicle que era llevado hasta Chetumal en barcos y entregado a la Federación de Cooperativas, institución fundada en 1940.

El capataz, llamado también jefe de campo o encargado de campamento era la persona que enganchaba a los chicleros y los presentaba al administrador quien era el que conseguía las refacciones para los hatos a su cargo. El capataz era el que hacía las labores de monteo y quien escogía el sitio en el que se levantaría el campamento.

El campamento debía estar cerca de alguna aguada o laguneta, nunca en el monte blanco sino en el zapotal que generalmente se hallaba en plena montaña, después de los bajos. Si no era posible colocarlo cerca de la aguada, se contrataba un aguador.

Una vez avituallados, los chicleros iban a chiclear. Partían de la central no sin antes disfrutar de una gran fiesta que ellos organizaban para despedirse de sus familiares, ya que pasaban varios meses en la montaña. Muchos de ellos nunca regresaban.

Generalmente partían los chicleros dos o tres días antes de que lo hicieran las cocineras y los arrieros. Con sus machetes picamonte afilados con piedra de mollejón, los que iban al frente abrían brechas que ensanchaban los de atrás transformándolas en caminos de herradura para que por ellos transitaran las arrias. El capataz iba al frente, y él era quien dirigía la caravana pedestre. Desde ese momento empezaba su labor de monteo, se orientaba con el sol y por la luz sabía la hora del día, escuchaba el croar de las ranas para localizar aguadas. Caminaban varias leguas hasta llegar al lugar elegido.

Una vez en el sitio que se destinaba para instalar el campamento, el capataz distribuía las tareas, ayudaba a derribar los árboles 
para construir las champas, etc. El camino de la central al campamento duraba varios días, pero una vez que habían llegado era necesario ponerse a trabajar para recibir a los que faltaban.

Lo primero que se instalaba era la champa para la cocina. En ella se hacían los guisanderos: uno a ras del suelo para las ollas grandes y otro más arriba para echar las tortillas, freír, etc. En la cocina se hacía el cuarto para la cocinera y éste era el único en todo el campamento que tenía paredes de guano.

También se levantaba el cocinadero para cocinar el chicle, en él se instalaba la hornilla de barro para que la resina recibiera el calor con uniformidad, y a veces se disponía de lugares para asentar los depósitos en sus bases procurando que los cobucones no llegaran al suelo para evitar que la resina se humedeciera.

Hechos la cocina y el cocinadero, se iniciaba la construcción de los hatos para que la chiclerada durmiera; antes lo había hecho en los arrimaditos que eran casas provisionales de fácil fabricación.

En cuanto llegaban las primeras arrias al campamento, éste tomaba vida, pues era la cocinera quien muchas veces movía a los chicleros. Se descargaba a las bestias, se les daba de comer y de beber y descansaban los arrieros.

Las arrias salían de la central cada quince días con los víveres e iban haciendo escalas cada jornada en los parajes rumbo al hato. En ellos a veces había un ramonero si las arrias eran bastantes; si no, los arrieros ramoneaban y alimentaban a las bestias con $r a-$ món, cubrían la mercancía con los trapoles y descansaban. Al día siguiente continuaban. Cuando el patacho era muy grande, se contrataba un jalayegua.

Las arrias eran el único medio de transporte, y muchas de ellas se perdieron con todo y cargamento al ser arrastradas por la corriente producida por las abundantes lluvias. Hoy los chicleros se transportan en bicicletas, van a su trabajadero y regresan el mismo día con su chivo lleno; por ello, el hato ha ido desapareciendo del paisaje del zapotal.

\section{Utensilios}

Los utensilios los proporcionaba la Cooperativa y eran abonados a la cuenta de los chicleros (menos los espolones y el machete que sí eran de su propiedad). Al terminar la temporada, devolvían el equipo a la Cooperativa y ésta les regresaba su dinero. 
Las herramientas que usaba el chiclero en su tarea diaria eran: la costalía, los machetes moruna y pando bien despalmados, la lazadera o lechuguilla, la bolsa aparadora, la bolsa recogedora, el chivo, el depósito, los espolones. Además llevaba en la costalía cerillos, un poco de petróleo, el lonch y la cantimplora. Cubriéndole toda la ropa llevaba la manga.

\section{El corte}

Para empezar el corte hay que limpiar alrededor del árbol, quitarle muy bien los sesgos de palo. Se preparaba la base del tronco, se chipeaba la cáscara para hacer la cuchara hasta que aparecía el sámago. Una vez desconchado el palo, se empezaba a picar, se practicaban dos cortes al tronco y rápidamente en la base, con un corte hacia arriba, se hacía la cuchara en la que se colocaba la bolsa aparadora que pendía de un clavo de madera puesto en el tronco.

Se tronqueaba el árbol en brazadas. Luego, el chiclero echaba mano de la lazadera para escalarlo. El espejo de corte debía ser exacto en tamaño y profundidad para que escurriera bien la resina del árbol. Había que tener mucho cuidado al cortar, pues a veces el machete solía enconcharse y al dar el siguiente golpe podía resbalar y cortar la lazadera, lo que significaba caer al vacío y no poder contarlo. Cuando se terminaba de trabajar el tronco, se pasaba a las ramas para florear el árbol y hacer que la madera coleara, aunque esto pudiera provocar la muerte de la planta a pesar de estar samaguda.

Si el árbol ya había sido trabajado y no parecía haber encallado aún, se le podía hacer por la otra cara un corte abotonado o un corte de manito de lagarto. Así era la labor de picar del chiclero. La técnica no ha cambiado, pues sigue siendo la misma desde hace cuarenta o cincuenta años. Cuando terminaba con un árbol, se pasaba a otro y así sucesivamente desde las cinco de la mañana hasta las cinco o seis de la tarde.

$\mathrm{Al}$ concluir de picar, empezaba a recoger y a vaciar el contenido de las bolsas aparadoras en otra más grande llamada recogedora y de ésta pasaba la resina al chivo que no es más grande pero sí más fácil de cargar.

A veces comía en su picadero al cual ya le había hecho su dobladito, amordazaba su chivo y partía del trabajadero rumbo al campamento. 
En cuanto llegaba, vaciaba el chivo en el depósito de su hato o en el cocinadero e iba hacia la cocina. Ahí comía en las mesas de majagua y se refrescaba en la aguada.

\section{Cocimiento}

El chicle resulta de la deshidratación de la resina del chicozapote, por lo que hay que cocerla. Esta labor se realizaba generalmente los sábados y los domingos.

$\mathrm{Su}$ proceso de cocimiento es el siguiente: la paila se llena a dos tercios de su capacidad y se pone a fuego lento en el cocinadero. Se vigila el chicle hasta que se dé el punto de cuajado (se ve un color ahumado amarillento en la espuma). Se gira el chamol despacio introduciéndolo 20 o 25 centímetros en la espuma; se acelera el movimiento hasta que esté cuajada la resina, luego se mete el chamol hasta el fondo de la paila y se mueve parejo para que reviente el hervor; entonces el giro es constante pero más lento. Conforme se cuece el chicle el fuego debe ser más bajo.

Una vez cocido, se retira la paila de la hornilla de barro y se coloca sobre tres estacas procurando que no roce el suelo. Más tarde, aún caliente, se vacía el chicle sobre una manta con jabón. Ahí el chiclero se encarga de hacer pelotas más o menos del tamaño de una marqueta. Luego toma el marquetero que ya ha sido enjabonado y enmarqueta el chicle aplastándolo con los puños y alisándolo con las manos jabonosas. Finalmente le imprime sus iniciales. El contratista también pone las suyas. Así continúa hasta que enmarqueta todo su chicle.

Esta labor ardua que se realiza en el cocinadero es la más delicada, pues el chicle debe quedar con el grado de humedad requerido por la Cooperativa.

Durante el cocimiento participaba toda la chiclerada. A veces el capataz era quien daba el punto de cuajado. Cuando el chiclero no sabía cómo dárselo, sus compañeros en tono de burla le decían "toma tu xate" que es una raíz usada en el cuajado. El cocimiento duraba varias horas, a veces toda la noche del sábado había movimiento en el cocinadero. 
Transporte

Las arrias que llevaban los víveres al hato transportaban de regreso el chicle ya cocido. El pesador se encargaba de pesar los quintales producidos aunque a veces lo hacía el capataz. Se cargaba a las bestias con el chicle enfardelado y partía el patacho.

En la central, el chicle era recibido por el pignorador, quien después de desenfardelarlo realizaba el cale (ahora existen laboratorios para medir la humedad), lo pesaba, hacía el romaneo y lo destinaba a la bodega donde se enfardelaba por el enfardelador en quintales (ahora en kilos) para su exportación.

\section{Comida y riesgos}

La chiclerada se alimentaba muchas veces de carne de animales de monte: pavos, tepescuintles, armadillos, jabalíes, venados, etc. También comía productos enlatados de importación o guisos como el fobló de origen beliceño. La cocinera hacía el pan: caprichos, queques, fritas, hojarascas, tortillas de harina, etc.

La montaña tiene sus peligros. Abundan los insectos como la mosca chiclera, el colmoyote, el rodador, el chaquiste y otros más. También hay víboras como la cuatro narices o nauyaca, cascabel y coralillo. Por fortuna los chicleros conocen muy bien la contrayerba y el viperol que utilizan como antiviperinos.

Cumplida la temporada, el chiclero regresaba a la central y cobraba. A veces dilapidaba sus haberes en parrandas, lo que ocasionaba que tuviera que pedir el anticipo de la siguiente temporada, o bien se dedicaba al corte de la caoba durante la época de secas.

\section{LÉXICO CHICLERO}

\section{Ambiente físico}

1.1. Montaña. Lugar donde trabaja el chiclero durante la temporada de extracción del chicle. Se le llama así por su relación con monte y no porque se refiera a cierta elevación del terreno. Francisco Santamaría ${ }^{4}$ dice que en la región ístmica del su-

\footnotetext{
${ }^{4}$ Diccionario de mexicanismos, Porrúa, México, 1984.
} 
reste de México se denomina así a la "selva virgen, por oposición al campo y aun al acahual", y también en Guatemala se le conoce con ese nombre.

1.2. Montear. Acción de buscar en el monte el sitio ideal para desarrollar el trabajo. "Un capataz debe saber montear" dicen los chicleros refiriéndose a que el lugar elegido debe ser el adecuado. Dice Santamaría que es "andar por los bosques buscando algo; especialmente buscar y localizar árboles de madera preciosa, en los trabajos de montería en el sureste".

1.3. Monte blanco. Monte donde no hay árboles de chicozapote, por oposición al zapotal.

1.4. Zapotal. Conjunto de árboles de chicozapote que puebla la selva. No tiene una extensión determinada.

1.5. Bajo. Tipo de monte de mínima altura, tupido de maleza donde abunda el zacate llamado wech o navajuela. Este tipo de zacate se nombra así porque produce granos en el cuerpo y mucha comezón. Su etimología probable es del maya wech 'sarna'.

1.6. Camino de herradura. Acceso abierto por los chicleros para que por él transiten las arrias. La referencia a herradura se explica por las herraduras que llevan las mulas en sus cascos.

1.7. Paraje. Champa construida en la orilla de los caminos de herradura para descargar las bestias, darles de comer y descansar. A veces hay en él un ramonero que alimenta a los animales.

1.8. Trabajadero. Lugar donde trabaja el chiclero. Rosario Gutiérrez ${ }^{5}$ dice que es el sitio donde se trabaja, ya cuidando los sembradíos, cortando madera, sacando chicle, etc. Santamaría argumenta que es el lugar donde habitual o temporalmente se está haciendo algún trabajo de campo o monte para un sembrado, para un cultivo u otra operación. Es una voz socorrida en el lenguaje campesino en el sureste.

1.9. Laguneta. Laguna pequeña pero más grande que la aguada.

1.10. Zapote. Árbol del que se extrae la resina para producir el chicle, también lo nombran con el genérico palo. La denominación chicozapote tiene una vitalidad menor, ya que casi no la documenté. La variedad que se explota en la región es $M a-$ nilkara zapota. Existen diferentes tipos de palo, comentaron algunos. Uno es el zapote huesudo que tiene poca resina y cáscara

5 "Cómo hablamos en Tabasco", Investigaciones Lingüisticas, México, 1 (1933), 265-312. 
gruesa; otro es el zapote morado que tiene mucho sámago y por lo tanto es rendidor en cuanto a la producción de chicle.

1.11. Majagua o mahahua. Árbol que partido en bejucos tiene varios usos. Una variedad de la majagua es la majagua palencana o majagua blanca que es una madera dócil utilizada en el campamento chiclero para hacer estantes, bateas, mesas y bancas. La vitalidad de la palabra se hace presente en la toponimia Mahahual en la costa sur de Quintana Roo, muy cerca de Chetumal.

1.12. Ramón. Forraje que comen las bestias durante el trayecto de la central al campamento. En maya se le denomina ox. Su nombre científico es Brosimum allicastrum. Santamaría dice que es un árbol silvestre de la zona tropical. Es excelente forraje para el ganado en tiempo de sequía. Abunda en la tierra caliente, sobre todo a orillas de los ríos, en los que caen los frutos.

\section{Personas y oficios}

2.1. Chicle. Producto que se obtiene de la resina del chicozapote. Dice Santamaría que es una gomorresina que fluye del tronco de este árbol, y se extrae haciéndole incisiones a éste al comenzar la estación de las lluvias.

2.2. Chiclero. Persona que se dedica a extraer la resina del árbol de chicozapote.

2.3. Chiclear. Acción de producir chicle desde su extracción hasta su cocimiento. Santamaría describe esta acción que comprende desde la elección del árbol y el corte de éste hasta el cocimiento de la resina. Explotar el chicle, principalmente para la exportación en las grandes selvas vírgenes. Algunos encuestados mencionaron enchiclar, que es untar chicle en alguna superficie: "Para hacer una batea en el campamento, se enchiclaba una manta y se adhería a los trozos de majagua para que no se saliera el agua".

2.4. Chiclerada. Conjunto de chicleros. Por ejemplo: los llamados tuxpeños formaban una chiclerada; fue un grupo de chicleros provenientes de Tuxpan, Veracruz, que se aposentó en el sur de Campeche y Quintana Roo en la década de 1930. Durante su estancia estos hombres dejaron los siguientes versos que recogí de un nostálgico chiclero chetumaleño: 
Cuando salimos de Tuxpan

para esta tierra afamada

qué gritería tan brusca

formaba la chiclerada.

2.5. Enganchar. Acción de contratar o apalabrar al chiclero para la temporada de explotación de chicle y/o de caoba.

2.6. Permisionario. Persona que solicitaba permiso a la Federación de Cooperativas para explotar chicle en terrenos nacionales o ejidos. Firmaba un contrato con esta Federación, pero no era socio de ella.

2.7. Jefe de campo o encargado de campamento. Persona que, además de distribuir el trabajo en el campamento, se encargaba de apuntar la cantidad de víveres y utensilios de trabajo que se le solicitaba, recibía el chicle ya cocido que se producía, aunque algunos además se dedicaban a su producción, ya que por este trabajo recibían una bonificación por cada quintal producido.

2.8. Pignorador. Persona responsable ante la Federación de Cooperativas de recibir, pesar, verificar la humedad y calar el chicle en la central. Destinaba el chicle para la bodega. Era asalariado, no socio y recibía una bonificación por cada kilo de chicle.

2.9. Quincenal. Dinero que se daba a la familia de los chicleros cada quince días.

2.10. Ramonero. Persona encargada de dar de comer ramón a las bestias de carga.

2.11. Ramonear. Acción de dar de comer ramón a las bestias. Santamaría lo confirma cuando dice que en Tabasco y región común del sureste es alimentarse los animales con hojas de $r a-$ món en tiempos de sequía o a falta de otra pastura.

2.12. Pesador. Persona que pesa el chicle en el campamento. Comentaron algunos encuestados que a veces es el capataz quien desempeña esta función. De los pesadores - que dependían directamente del administrador- dice Federico Heuer ${ }^{6}$ que "son los que tienen como ocupación la de visitar los hatos para recibir y pesar el chicle producido".

2.13. Quintal. Unidad de peso utilizada por los chicleros, es el equivalente a 46 kilos.

2.14. Calar. Acción de calcular la humedad del chicle por medio de una incisión en el producto.

${ }^{6}$ La industria del chicle, tesis de licenciatura, UNAM, México, 1945. 
2.15. Romaneo. En la lengua de los chicleros comprende al menos dos acciones: pesar el chicle y levantar el informe; ambas actividades las llevaban a cabo el pignorador o el administrador. El DRAE dice que es acción y efecto de romanear que es pesar con la (balanza) romana.

2.16. Enfardelar. Acción de hacer fardos con el chicle. Generalmente éstos son de 46 kilos. Ponce documenta que "en Campeche se dice enfadergar: ...se enfadergaba y salía listo para la exportación”.

2.17. Desenfardelar. Acción de deshacer los fardos.

2.18. Enfardelador. Persona que se dedica a enfardelar el chicle.

\section{El campamento}

3.1. Hato o champa. Construcción donde duermen los chicleros. Dice Ponce que hato designa también a todo el campamento chiclero (conjunto de champas, cocinadero, etc.). También es la posada en general; campamento en las monterías según Santamaría.

El DRAE registra hato como de origen incierto y dice que es un sitio fuera de las poblaciones que eligen los pastores para comer y dormir durante su permanencia allí con el ganado; también señala que es una porción de ganado. Con seguridad, se puede afirmar que del léxico ganadero ha pasado al chiclero con el mismo significado de 'conjunto' o 'grupo', pues es vocablo propio de la montería. Sin embargo, Lourdes Gavaldón ${ }^{7}$ nunca lo menciona, aunque sí aparece en sus nóminas sobre la ganadería hatajo "que es el rebaño de chivos". Corominas $^{8}$ dice que con el significado de 'rebaño' aparece en Juan Ruiz la cabeza de los hatos que se cita en el Libro de la montería (siglo xIv, t. 2, p. 303). En El libro de buen amor puede leerse "a grand hato daría grand lucha e conquista" (1011c) con el significado de "rebaño', y "desbuélvete de aqués hato" (971d) con el de 'vestido', 'ropa', al igual que en la estrofa 1472b "suelas rotas e paños rotos e viejos hatos".

${ }^{7}$ El habla de Melchor Múzquiz, Coahuila. Aspectos fonéticos y léxico ganadero, tesis de licenciatura, UNAM, México, 1971.

${ }^{8}$ Diccionario crítico-etimológico castellano e hispánico, Espasa Calpe, Madrid, 1980-1983. 
José María Aguado ${ }^{9}$ dice que proviene del germánico fat y cita los versos 1472, 971, 1011 y 968 de la obra del Arcipreste de Hita antes aludida. Además menciona que en el Guzmán de Alfarache (II, 5) también aparece "dionos una rociada de leña seca, sacudiéndonos el polvo del hatillo de manera que nos levantó ronchas por todo el cuerpo". Por otro lado, Poot dice que en maya es jaato'ob < jaato 'jacal' y ob (plural): 'jacales', y menciona que puede ser de origen maya pues existe $j a$ 'casa' en quiché, sin embargo no asegura tal origen porque en maya yucateco 'casa' es na. La situación dubitativa de Poot en su análisis, a la que se suman las citas de Corominas y mías, hace suponer que no es vocablo de origen americano.

En cuanto a champa, Ponce dice que es un cobertizo de guano sin paredes también llamado hato. Es una especie de caseta - apunta Gutiérrez-formada por seis palos; los cuatro más bajos van en los cuatro ángulos y dos más altos van en la parte de en medio; arriba se les pone techo de palma y ahí descansan las personas, no tiene puertas ni está cerrada.

3.2. Guisandero. Sitio de la cocina donde está el fuego.

3.3. Arrimadito. Construcción provisional; consiste en un arco rectangular que se levanta en el monte y se cubre de guano de pezón (pata) ancho, de tal modo que el guano forma una especie de techo que llega hasta el suelo. Del palo horizontal el chiclero cuelga su hamaca y ahí pasa la noche. Es una construcción muy semejante al bendito argentino que registra Tito Suabidet ${ }^{10}$ pero que se fabrica con cuero en vez de guano.

3.4. Comidas. Anoto a continuación algunas de las comidas que consumen normalmente los chicleros durante su estancia en el monte.

Capricho. Pan de dulce en forma de concha.

Queque. Pan de sal o azúcar de origen beliceño. Es redondo, ancho y pequeño adornado con minúsculos agujeros hechos con un tenedor u otro objeto.

Frita. Tortilla dulce y gruesa de harina que se parte por la mitad y se fríe en aceite.

Hojarasca. Tortilla fina y grande que se fríe y se baña con azúcar.

Fobló. Pan de sal hervido en agua. "Es comida de gente de color", comentaron algunos chicleros.

${ }^{9}$ Glosario sobre Juan Ruiz. Poeta castellano del siglo XIV, s.e., Madrid, 1929.

10 Vocabulario y refranero criollo, Guillermo Kraft, Buenos Aires, 1952. 
"Se comía mucha carne de monte", aseguraron los chicleros, como faisanes (Crax' rubra), cojolites (Penelope purpurasen), pavos (Meleagris ocellata), venados (Mazama americana), jabalíes (Tayassu tajacu), jahuilla (Tayassu pecari), armadillo (Agouti pa$c a$ ), tepezcuintle (Dasypus movencinctus) y kitan (Pácarid warf). "También comíamos tamales de cojolites envueltos en hojas de chit" (Thrinax radiata), mencionó uno de los encuestados.

3.5. Animales. Anoto los animales que mencionaron los encuestados como abundantes y dañinos.

Mosca chiclera (Pseudo fercia vulturis). Insecto que pica a los chicleros y causa gran infección en la piel.

Colmoyote. Díptero grande, de extremidades muy largas, que al picar deposita una larva o gusano blando, retorcido, corto y grueso.

Rodador (Simulia maculata). Santamaría menciona que es una especie de mosquito diminuto, llamado así porque al llenarse con la sangre que chupa, rueda y cae como la sanguijuela. Se le llama igual en Cuba.

Chaquiste. Insecto pequeño y negro que pica la piel y causa mucha comezón.

Nauyaca (Bothrops yucatanicus). Terrible víbora de activa ponzoña mortal, llamada así en Tabasco y región circunvecina. Algunos chicleros dijeron que uno puede salvarse de la mordedura de la nauyaca comiéndose vivo al animal. También dijeron conocer la víbora de cascabel (Crotalus durisus), coralillo (Micrurus diastema) y colehueso, todas muy venenosas.

3.6. Contrayerba. Bejuco que, machacado y hervido o sólo masticado, es un excelente antiviperino que protege de la mordedura de la nauyaca o cuatro narices. Ponce dice que en Campeche se le conoce como antiyerba, "una raíz que se da mucho en la montaña". Santamaría sólo dice que es una planta de la familia de las moráceas (Dorstenia contrajerva).

\section{Utensilios}

4.1. Picamonte. Machete usado para abrir las brechas en la selva.

4.2. Moruna. Machete angosto y largo usado para picar el árbol de chicozapote.

4.3. Pando. Tipo de machete curvo que se usa para picar el árbol de chicozapote. Mide por lo general 70 centímetros de largo y 6 o 7 de ancho. 
4.4. Mollejón (piedra de). Piedra que sirve para afilar el machete. Se usa una muy fina para asentar el filo del machete y otra rústica para afilarlo, comentaron los entrevistados.

4.5. Despalmado. Calificativo del machete muy filoso.

4.6. Espolón o chuzo. Herramienta de hierro que se pone el chiclero en los pies para poder escalar el árbol con facilidad; Poot anota que, en Quintana Roo, fueron los tuxpeños los que usaron primero los espolones. Uno de los informantes mencionó que cuando no usaban espolones trabajaban a pata pelada.

4.7. Costalía o shalbec. Bolsa grande en la que el chiclero lleva todo su equipo de trabajo. También se le conoce como shalbec y más comúnmente garnil que es un morral o "bolsa de cuero pendiente del cinto y con varias divisiones" (DRAE).

4.8. Chivo. Bolsa en la que el chiclero transporta desde el trabajadero al campamento la resina. Es un recipiente de lona que tiene capacidad para 10 o 12 kilos aunque los hay más grandes. En él se vacía el contenido de la bolsa recogedora. Heuer dice que también se le llama cargadora, voz que nunca documenté durante las encuestas.

4.9. Lazadera o lechuguilla. Cuerda con la que el chiclero se ata por la espalda al árbol. También la nombran con el genérico soga. Es de vital importancia su uso, pues con ella se llegaba hasta las partes más altas del árbol.

4.10. Aparadora. Bolsa que se adhiere a la base del árbol para que en ella caiga la resina. Es una bolsa de manta que puede tener varios tamaños.

4.11. Recogedora. Bolsa en la que se concentra el contenido de las aparadoras. Tiene capacidad para 12 kilos.

\section{Extracción del chicle}

5.1. Chipiar. Acción de raspar la cáscara del árbol para hacer la cuchara.

5.2. Cáscara o concha. Corteza del árbol.

5.3. Desconchar. Acción de quitar la cáscara o concha del árbol con el machete hasta que aparezca el sámago.

5.4. Sámago. Parte del árbol que recibe el corte para que por ella escurra la resina. Es la albura o parte más blanda de la madera, que no es recomendable para la construcción

5.5. Samagudo. Calificativo que se da al árbol que tiene gran cantidad de sámago. 
5.6. Picar. Acción de practicar incisiones en el árbol para extraer la resina. Santamaría dice que en Tabasco, en el lenguaje de la montería es castrar el hule, el chicle o árboles semejantes haciendo incisiones en el tallo, para que mane el látex, savia o resina. Luis Jiménez ${ }^{11}$ habla de castrar o calar el árbol para ver si éste puede ser explotado y señala algunos tipos de picado como el lengüeta, que consiste en hacer incisiones en una sola faja longitudinal del árbol, que abarque únicamente la tercera parte de la circunferencia de éste; el picado pluma o espinas de pescado que consiste en un canal vertical al que concurren los cortes oblicuos; y finalmente el picado espiral en el que las incisiones se efectúan alrededor del árbol. Señala además que el corte más aconsejable es el lengüeta-éste es precisamente el que hacen los chicleros que entrevisté-pues no daña tanto al árbol, mientras que los otros dos pueden producir la muerte de la planta.

5.7. Florear (el árbol). Acción de picar el árbol completamente desde la base hasta las ramas más altas.

5.8. Tronquear. Acción de picar el tronco del árbol. Esta acción comprende desde poner la bolsa aparadora hasta trabajar 'picar' el tronco del árbol; luego el chiclero se ata a la lazadera para empezar a picar más alto.

5.9. Brazada o brazo. Cada una de las líneas de cortes que se hacen al árbol.

5.10. Espejo de corte. Corte practicado en el sámago y que brilla al otro día pues refleja -como espejo-los rayos del sol.

5.11. Resina o chicle. Látex que mana del árbol de chicozapote. Chicle y resina en este contexto parecen ser sinónimos para algunos chicleros, sin embargo, otros mencionaron que es resina, y que cuando ésta "ya se coce se llama chicle".

5.12. Colear (el árbol). Acción de escurrir toda la resina del árbol. Cuando esto ocurre, el árbol puede morir o tardar muchos años en producirla en cantidad considerable. Cuando al árbol escurre su última resina a ésta se le denomina colita.

5.13. Enconcharse (el machete). Quedarse en el machete algún residuo de la concha del árbol. Esta situación es peligrosa - comentaron- pues al dar el corte, el machete puede resbalar y cortar la lazadera. "Muchos de mis amigos así murieron", comentó un chiclero experimentado.

${ }^{11}$ El chicle: su explotación forestal e industrial, Imprenta Manuel Casas, México, 1951. 
5.14. Encallar (el árbol). Borrarse del tronco del árbol los cortes de los chicleros. El período de un árbol para encallar es de aproximadamente cinco años, aseguraron algunos, y antes de ese tiempo no es recomendable explotarlo pues puede morir o producir escasa resina.

5.15. Corte abotonado. Corte que se practica en el árbol por la parte posterior donde no fueron cerradas o terminadas las brazadas hechas en la parte delantera.

5.16. Manito de lagarto. Corte que se le hace al árbol por los costados cuando éste ya ha sido trabajado por sus partes delantera y trasera. Son dos cortes a la izquierda -me aseguró un informante $-\mathrm{y}$ dos a la derecha de forma casi vertical para hacer más rápido el descenso de la resina.

5.17. Picadero. Vereda o rumbo donde trabaja el chiclero. Ponce dice que en Campeche es la zona de árboles de chicozapote seleccionada por el chiclero para trabajar.

5.18. Dobladito. Señales que consisten en doblar las ramas de ciertos arbustos por donde transita el chiclero para indicar su rumbo y no perderse en el monte. "A estas señales, que son señales de picadero, a veces, para engañar a otro chiclero con el objeto de que no te gane tus zapotes o tu madera, les haces el doblez en sentido contrario al de tu avance; es decir como si caminaras hacia otro rumbo", comentó uno de los encuestados.

5.19. Amordazar. Acción de tapar la boca de la bolsa llamada chivo. Consiste en un amarre que se hace en la boca del chivo poniendo un palito y cubriéndolo con lodo o con el sámago del árbol para que la resina no se derrame.

5.20. Cobucón. Extremos inferiores de los depósitos. Estas puntas de la bolsa no deben rozar el suelo para que no se humedezca la resina; por eso el depósito debe asentarse sobre algo alto.

\section{Cocimiento}

6.1. Cocinadero. Sitio del campamento donde se cuece el chicle.

6.2. Paila. Cazo grande donde se cuece el chicle en el cocinadero. El DRAE dice que es una vasija grande de metal, redonda y poco profunda. "En cada pailada se cocinaban hasta setenta kilos de chicle", comentaron los chicleros.

6.3. Hornilla. Círculo formado por piedras en las que se asienta la paila para cocer el chicle. 
6.4. Chamol. Vara de madera dura que se utiliza para mover el chicle cuando éste se está cociendo.

6.5. Xate. Yerba que se usa durante el cocimiento del chicle para que éste no se derrame al hervir.

6.6. Marqueta. Trozo de chicle ya cocido con un peso aproximado de diez kilos. Ponce dice que lleva tres sellos: las iniciales del contratista, las del capataz y las del chiclero; sin embargo un informante aseguró que sólo lleva dos: las del contratista y las del chiclero. Santamaría dice que son bloques de hule, chicle y la panocha en bruto; lo mismo se dice de otras cosas como la pasta de tamarindo, el chocolate...

6.7. Marquetero. Rectángulo de madera donde se echa el chicle ya cocido. Poot dice que se construye con tablas de una medida aproximada de $40 \times 20 \mathrm{~cm}$.

\section{Transporte}

7.1. Arria. Conjunto de mulas, cinco de carga y una de silla. Las arrias fueron en su época el único medio de transporte de las provisiones y del chicle.

7.2. Patacho. Conjunto de treinta mulas aproximadamente. Santamaría dice que es una pequeña recua de bestias mulares, arria diestra en el oficio de cargar y viajar en México y Honduras.

7.3. Jalayegua. Persona que jala la yegua que va al frente del patacho.

7.4. Trapol. Manta con la que se cubrían las mercancías que llevaban las arrias para protegerlas de la lluvia.

7.5. Jornada. Tiempo que se hace desde la Central hasta el primer paraje; "El camino de la Central a los hatos está compuesto de varias jornadas", comentaron algunos chicleros.

\section{Conclusiones}

Las observaciones siguientes están basadas exclusivamente en los materiales que se obtuvieron en las encuestas.

Este léxico no tiene la característica de ser exclusivo de los chicleros o de las personas que estuvieron o están en contacto con ellos, sino que su uso matiza, en diversas situaciones, el habla de la comunidad chetumaleña: "se comió una paila de mandarinas", "se le enconchó el machete a mi compadre", "nos 
comimos unos queques recién horneados", "come ramón" (usado en torno de burla para decirle a alguien que es torpe como una bestia de carga), "mi abuelo chicleaba cerca de Cozumel".

Por otro lado, la aplicación de las encuestas y todo el trabajo de investigación puede considerarse como una labor de rescate de un léxico que irá perdiéndose seguramente, a causa de la decadencia de la industria de la extracción del chicle en esta zona de México.

\section{Fonética}

a) Apócope: chamol por chamolsóchil.

b) Conservación de la antigua $h$ aspirada: [xáto] o [háto].

c) Aspiración de /x/: [hornáda] que es característica de esta zona del país ${ }^{12}$.

\section{Morfosintaxis}

a) Formación de palabras: verbo + nombre: picamonte, jalayegua.

b) Formaciones con prefijos: en-: enchiclar.

c) Formaciones sufijales: - ada (conjunto): chiclerada; -adero (lugar de la acción): trabajadero, picadero, cocinadero, guisandero; -al (lugar, abundancia): zapotal; -ero (oficio): ramonero; (instrumento): marquetero, lazadera; -ía (cualidad) : costalia;-ol (aumentativo) trapol; -udo (cualidad de abundancia): samagudo.

\section{Léxico y semántica}

a) Formación de nuevos términos por derivación, composición: chiclerada 'conjunto de chicleros'. Formación con el sufijo - $a d a$, que en opinión de Tudora Sandru ${ }^{13}$ es el sufijo más

12 Véase el mapa 47 del Atlas Lingüistico de México, t. 1, vol. I: Fonética, F.C.E.-UNAM-El Colegio de México, México, 1990, y más precisamente el análisis de José Moreno de Alba, La pronunciación del español en México, El Colegio de México, México, 1994.

13 "Observaciones sobre la formación de palabras en el español americano: tipos producidos de la derivación por sufijos”, $R R L, 22$ (1977) citado por José Moreno de Alba, Morfología derivativa nominal en el español de México, UNAM, México, 1987, p. 46. 
productivo de la formación nominal dentro del español americano, opinión que comparte Charles Kany ${ }^{14}$. Se trata de un sustantivo derivado de otro sustantivo en cuya formación intervienen el indigenismo chicle más el sufijo - ada con el significado de conjunto. En el trabajo de Hans Marchand ${ }^{15}$ citado por Moreno de Alba (p. 46, nota 70), pudiera llegar a suponerse que con base en lo presentado en dicha nota: "prácticamente ninguna voz derivada con este sufijo tiene etimología latina" - análogo al caso chiclerada-, este sufijo, no por su estructura fonológica sino por el sentido que adquiere, es español y no latino. Esta formación verifica, al menos con un caso más de los 29 que documenta Moreno de Alba, el origen hispánico de - ada que él contempla; trabajadero 'sitio donde trabaja el chiclero'. Formación con el verbo trabajar más el sufijo -adero que, cuando se agrega a la raíz del verbo - como en este caso-denota lugar de la acción según Kany (p. 97). Formación similar tienen en español lavadero y matadero; cocinadero 'sitio donde se cuece el chicle'. Formación con el verbo cocinar más el sufijo -adero que, como en el caso anterior, denota el lugar donde se realiza la acción. La relación fonológica y semántica de esta voz derivada es clara con el verbo cocinar y con el sustantivo cocina, es decir con 'acción de cocer' y con 'lugar donde se cuece la comida'. Al tratarse de un sitio como la cocina 'lugar de la casa donde está el fuego' (DRAE), el cocinadero hace las veces de ésta, con la salvedad de que en él no se cuece la comida; guisandero 'sitio donde se guisa la comida'. Formación con el verbo guisar 'aderezar, sazonar la comida con especias' (DRAE) más el sufijo -adero con $n$ interfijal. En su formación, los chicleros han dado un matiz distinto al verbo del cual deriva esta palabra y lo han diferenciado de cocinar; trapol 'manta grande con que se cubren las mercancías para protegerlas de la lluvia'. Derivado del sustantivo trapo más el sufijo -ol muy poco productivo pero con gran relación semántica con la palabra primitiva. La Academia (Gramática) menciona que se trata, en masculino, de un apócope de -olo usado en la formación de diminutivos (baberol, farol). Sin embargo, la significación de aumentativo es la que consigna esta voz, significación semejante a la del sufijo-al

14 Semántica hispanoamericana, Aguilar, Madrid, 1962, citado por MoreNO DE Alba ( $i d$.$) .$

15 The categories and types of present-day English word-formation, a synchronic diachronic approach, C. H. Beck'śche, München, 1969. 
en ruidajal que, aunque no ha tenido una formación morfológica semejante, un hablante nativo no dudaría en relacionarla con ruido. Lo mismo sucede con trapol. Las pocas palabras que pueden formarse con el sufijo -ol, menos aún con el significado de aumentativo como el aquí estudiado, no mengua en nada la importancia de esta formación neológica.

b) Especializaciones semánticas: por alguna razón que la realidad lingüística crea -al ordenar el mundo material de los referentes-, los chicleros han diferenciado dos verbos que tienen todas las características de ser sinónimos: cocinar y guisar. En las respectivas entradas, el DRAE no los diferencia, pues ambos significan - con ciertas salvedades- 'aderezar las viandas'. Tal vez la definición de guisar parezca ser la más exacta pues ésta se relaciona con guiso que es el 'condimento o salsa que se echa en la vianda para guisarla y sazonarla' (DRAE), mientras que cocinar es 'componer y aderezar las viandas', empero también es 'guisar'.

En su necesidad de diferenciar topográficamente los dos sitios donde se lleva a cabo el cocimiento del chicle y de la comida, los chicleros han tenido que distinguir nominalmente ambos lugares y han formado dos nuevas palabras: guisandero y cocinadero; ello ha llevado a la especialización semántica de los verbos de los cuales se derivan.

Por un lado, el cocinadero es el sitio donde se cuece el chicle. Si se atiende a que solamente en ese lugar el chicle es cocido, se puede decir que ha habido una especialización del verbo $\mathrm{co}^{-}$ cinar del que deriva, pues a la resina no se le agrega ninguna otra sustancia o condimento para que tome la consistencia que debe tener. En otras palabras, cocinar es tomado como hervir o sancochar, pero no así como guisar. Por otro lado, el guisandero es el lugar de la cocina donde se cuecen los alimentos y donde no se cocina el chicle, pues su estructura no permite que ahí se lleve a cabo el cocimiento de la resina.

c) Recurso al término genérico. El genérico se usa con mayor frecuencia, pues el término específico por alguna razón ha caído en el olvido, y por tanto en el desuso: soga 'cuerda', reemplaza a lazadera y a lechuguilla; lumbre 'fuego', reemplaza a hornilla; zapote 'árbol de chicozapote', reemplaza a chicozapote.

d) Dislocación de sentido por proximidad espacial o similitud material o funcional: chamol 'vara de madera con que se mueve el chicle al cocerse'. Es una sinécdoque, pues se nombra no el objeto, sino el material (el tipo de madera, chamolsó- 
chil) con que está hecho; lechuguilla 'cuerda con que el chiclero se ata por la espalda para subir a las partes altas del árbol'. Corresponde a una sinécdoque, pues se nombra el material (Agave lechuguilla) con que está fabricada la cuerda.

e) Nuevas denominaciones por metáforas. Las metáforas que forman los chicleros son de las llamadas metáforas léxicas o lingüísticas como "pata de la silla". Es decir formas sencillas en cuanto a los elementos que se comparan y que generalmente corresponden a referentes del mundo material singular de la gente del campo. Anoto las más comunes: chivo 'bolsa en la que el chiclero transporta desde el trabajadero al campamento la resina reunida durante el día de labor'. La semejanza formal entre este recipiente y un chivo es el rasgo semántico que encuentro en esta denominación, pues los encuestados comentaron que cuando la bolsa está llena parece un chivo pequeño; florear 'acción de picar totalmente el árbol'. La relación semántica con abrirse como flor o florearse (dejar al descubierto toda la resina), creo, es el origen de esta metáfora; colear 'acción de escurrir toda la resina del árbol'. El movimiento en zigzag que hace la resina al descender por el tronco del árbol, es semejante al de los vagones de un tren en marcha, a uno y otro lado. De ahí, pienso, procede esta denominación; corte abotonado 'corte que se le practica al árbol por la parte posterior con el objeto de cerrar los hechos ya en la parte delantera'. La relación semántica con abotonar 'cerrar con el botón' es evidente, pues al practicar el corte abotonado, éste cierra la parte abierta o no picada del árbol; corte manito de lagarto 'corte casi vertical que se le hace al árbol'. La semejanza formal entre este tipo de corte y las patas o manos del lagarto es el origen de esta denominación a la que los indígenas mayas llaman kab-ain.

f) Voces de probable origen indígena: champa 'cobertizo de guano sin paredes'. Marius Sala ${ }^{16}$ dice que la voz procede del quechua. Además apunta que en algunos países sudamericanos significa 'enredo de ideas y conceptos'. Augusto Malaret ${ }^{17}$ argumenta que procede del quechua tampa que significa 'enredo', 'embrollo', mientras Marcos Morínigo ${ }^{18}$ dice que procede del quecha ch'ampa. Santamaría-mucho más cercano

16 El léxico indígena del español americano, Academia Mexicana-Editora Academici Romane, México-Bucarest, 1977.

17 Diccionario de americanismos, Emecé, Buenos Aires, 1946.

18 Diccionario de americanismos, Muchnik, Buenos Aires, 1985. 
al significado que se le da en los trabajos de montería- apunta que puede tener su etimología en campo, a través de acampar. Es una voz con gran vitalidad en el léxico chiclero, según pude constatar en varios de los encuestados; majagua 'cierto árbol de bejucos' (Hampea trilobata), Sala dice que es árbol en México, Nicaragua, Panamá, Costa Rica, Colombia, El Salvador, Venezuela. En Colombia es cuerda de henequén. En Cuba es chaqueta. En Panamá es fibra del tallo del plátano. Santamaría dice que es una voz de origen caribeño, que es un árbol de cuya corteza se obtiene una fibra semejante al yute usada en cordelería; chamol 'vara de madera dura que se usa para mover el chicle cuando éste se está cociendo'. De esta palabra dice Santamaría que es el nombre vulgar que en el estado de Guerrero (México) se da al tabachín o chascalsúchil, que es un arbusto de las tierras cálidas de la América tropical (Caesalpinia o Poinciana pulcherrima) y que tiene varios usos. Su madera es suave, ligera, de color anaranjado. Alfredo Neves ${ }^{19}$ lo documenta como Chamolsóchil o Chamolsúchil (voz náhuatl) con la clasificación Caesalpinia pulcherrima.

g) Préstamos de otras lenguas y adaptaciones fonéticas. Queque 'panecillo', del inglés cake; lonch 'almuerzo', del inglés lunch; garnil 'bolsa', del francés carnier, shalbec 'bolsa', del inglés shoot bag.

h) Sin precisar: chipiar 'quitar la corteza del árbol'. Tal vez se trate de una voz onomatopéyica, pues quizá así suene al oído del chiclero el machete al raspar el tronco del árbol; fobló 'especie de pan hervido'; xate 'planta que se usa en el cocimiento del chicle'. Sólo pude localizar -te que es un sufijo maya común de los nombres de árboles según Alfredo Barrera ${ }^{20}$. Posiblemente provenga de xiaat que es una palma (Chamaedorea seifrizii) conocida en la zona más el sufijo -te.

\footnotetext{
Raúl Arístides Pérez Aguilar Universidad de Quintana Roo
}

19 Diccionario de americanismos, Sopena, Buenos Aires, 1973.

20 Diccionario maya-español, Porrúa, México, 1991. 


\section{APÉNDICE 1 \\ ÍNDICE DE PALABRAS}

Amordazar 5.19.

Arria 7.1.

Arrimadito 3.3.

Bajo 1.5.

Bendito 3.3

Bolsa aparadora 4.10.

Bolsa recogedora 4.11.

Brazada 5.9.

Brazo 5.9.

Calar 2.14.

Camino de herradura 1.6.

Capricho 3.4.

Cargadora 4.8.

Castrar 5.7.

Cobucón 5.20.

Cocinadero 6.1.

Cojolite 3.4.

Colear 5.12.

Colehueso 3.5.

Colita 5.13.

Colmoyote 3.5.

Concha 5.2.

Contrayerba 3.6.

Corte abotonado 5.15.

Costalía 4.7.

Chamol 6.4.

Champa 1.7, 3.1.

Chaquiste 3.5.

Chicle 2.1, 5.1.

Chiclear 2.3.

Chiclerada 2.4.

Chiclero 2.2.

Chicozapote 1.10.

Chipiar 5.1.

Chit 3.5.

Chivo 4.8 .

Chuzo 4.6.

Desconchar 5.3.

Desenfardelar 2.17.

Despalmado 4.5.

Dobladito 5.18.
Encallar 5.14.

Encargado de campamento 2.7.

Enconchar 5.13.

Enchiclar 2.2.

Enfadergar 2.16.

Enfardelador 2.18.

Enfardelar 2.16.

Enganchar 2.5.

Enmarquetar 6.7.

Espejo de corte 5.10.

Espolón 4.6.

Faisán 3.4.

Florear 5.7.

Fobló 3.4.

Frita 3.4.

Garnil 4.7.

Guisandero 3.2.

Hato 3.1.

Hojarasca 3.4.

Hornilla 6.3.

Jaato'ob 3.1.

Jabalí 3.4.

Jahuilla 3.4.

Jalayegua 7.3.

Jefe de campo 2.7.

Jornada 7.5.

Kitan 3.4.

Laguneta 1.9.

Lazadera 4.9.

Lechuguilla 4.9.

Mahahua o majagua 1.11 .

Manito de lagarto 5.16.

Marqueta 6.6.

Marquetero 6.7.

Mollejón (piedra de) 4.4.

Montaña 1.1.

Monte blanco 1.3.

Montear 1.2.
Moruna 4.2.

Mosca chiclera 3.6.

Ox 1.12.

Paila 6.2.

Pailada 6.2.

Pando 4.3.

Paraje 1.7.

Patacho 7.2.

Permisionario 2.6.

Pesador 2.12.

Picadero 5.17.

Picado espinas de pescado 5.6.

Picado espiral 5.6.

Picado lengüeta 5.6.

Picado pluma 5.6.

Picamonte 4.1.

Picar 5.6.

Pignorador 2.8.

Queque 3.4.

Quincenal 2.9.

Quintal 2.13.

Ramón 1.12.

Ramonear 2.11.

Ramonero 2.10.

Rodador 3.5.

Romaneo 2.15.

Sámago 5.4.

Samagudo 5.5.

Shalbec 4.7.

Soga 4.9.

Trabajadero 1.8.

Trapol 7.4.

Tronquear 5.8.

Venado 3.4.

Víbora de cascabel 3.5.

Xate 6.5.

Zapotal 1.4.

Zapote 1.10.

Zapote huesudo 1.10.

Zapote morado 1.10. 


\section{APÉNDICE 2}

Cuestionario

\section{Ambiente Físico}

1.1. ¿Cómo se llama el lugar donde trabaja el chiclero durante la temporada?

1.2. Acción de buscar en el monte el sitio exacto para desarrollar el trabajo.

1.3. Monte donde no hay árboles de chicozapote.

1.4. Conjunto de árboles de chicozapote.

1.5. Monte de escasa altura.

1.6. Camino por donde transitan las mulas.

1.7. Construcción a la orilla del camino que sirve para descansar.

1.8. Lugar del monte donde se trabaja.

1.9. Laguna pequeña pero más grande que la aguada.

1.10. Árbol del cual se extrae la resina.

1.11. Madera o bejuco muy usado en la construcción de casas, bateas, etc.

1.12. Forraje que comen las bestias.

\section{Personas y Oficios}

2.1. Producto que se hace con la resina del chicozapote.

2.2. Persona que se dedica a extraer la resina del chicozapote.

2.3. Acción de producir chicle, desde su extracción hasta su cocimiento.

2.4. Conjunto de chicleros.

2.5. Acción de contratar o apalabrar al chiclero para la temporada.

2.6. Persona que tiene permiso para explotar el chicle.

2.7. Persona que distribuye el trabajo en el campamento.

2.8. Persona que en la central recibe, pesa, verifica la humedad y cala el chicle.

2.9. Dinero que se da a la familia del chiclero cada quince días.

2.10. Persona que da de comer ramón a las bestias de carga.

2.11. Acción de cortar las hojas de ramón para dar a las bestias.

2.12. Persona que pesa el chicle en el campamento.

2.13. Unidad de peso equivalente a 46 kilogramos.

2.14. Acción de medir la humedad del chicle por medio de una incisión en el producto.

2.15. Acción de pesar el chicle y levantar el informe.

2.16. Acción de hacer fardos de chicle.

2.17. Acción de deshacer los fardos de chicle.

2.18. Persona que hace los fardos de chicle.

3. El CAMPAMENTO

3.1. Cada una de las construcciones donde duermen los chicleros.

3.2. Sitio de la cocina donde está el fuego.

3.3. Construcción provisional que hace el chiclero para dormir.

3.4. ¿Qué guisos comen?

3.5. ¿Qué animales son peligrosos en el monte?

3.6. Antiviperino que lleva el chiclero. 
4. Utensilios

4.1. Tipo de machete usado para abrir brechas en el monte.

4.2. Tipo de machete angosto y largo usado para picar el árbol de zapote.

4.3. Tipo de machete ancho y pequeño usado para picar el árbol de zapote.

4.4. Piedra que se usa para afilar los machetes.

4.5. Cuando el machete está muy filoso se dice que está bien...

4.6. Especie de espuela que se pone el chiclero en las botas para subir al árbol.

4.7. Bolsa grande que usa el chiclero para llevar todo su equipo.

4.8. Bolsa de lona que se usa para llevar la resina del trabajadero al campamento.

4.9. ¿Qué sostiene por la espalda al chiclero cuando está arriba del árbol?

4.10. Bolsa que se clava en la base de tronco del árbol para que en ella caiga la resina.

4.11. Bolsa en la que se echa la resina de las bolsas aparadoras.

5. EXTRACCIÓN DE CHICLE

5.1. Acción de raspar la corteza del árbol de chicozapote.

5.2. Cubierta gruesa del tronco del árbol.

5.3. Acción de quitar la cubierta del tronco del árbol con el machete.

5.4. Parte del tronco que recibe el corte para que escurra la resina.

5.5. ¿Cómo se le dice al árbol que tiene mucho sámago?

5.6. Acción de hacer incisiones en el tronco del árbol para extraer la resina.

5.7. Acción de picar el árbol completamente, desde el tronco hasta la última rama.

5.8. Acción de picar el tronco del árbol hasta donde alcance el chiclero.

5.9. Cada una de las líneas de cortes que se le hacen al árbol.

5.10. Corte hecho en el sámago que brilla con el sol.

5.11. Líquido que sale de los cortes.

5.12. Acción de echar toda su resina (el árbol).

5.13. Cuando el machete tiene algún residuo de la corteza, se dice que está...

5.14. Cuando al árbol se le han borrado los cortes, se dice que ha...

5.15. Corte que se le practica al árbol por la parte posterior donde no fueron erradas las brazadas.

5.16. Corte que se practica en el costado del árbol cuando éste ya ha sido trabajado por las caras delantera y trasera.

5.17. Zona de árboles de chicozapote seleccionada por el chiclero para trabajar.

5.18. Acción de doblar las ramas de ciertos arbustos por donde transita el chiclero para indicar su rumbo y no perderse en el monte.

5.19. Acción de cerrar la boca de la bolsa llamada chivo.

5.20. Cada uno de los extremos del depósito donde se concentra el chicle antes de su cocimiento.

6. Cocimiento

6.1. Sitio del campamento donde se cocina el chicle.

6.2. Recipiente donde se echa la resina para su cocimiento.

6.3. ¿Dónde se asienta la paila?

6.4. Vara de madera con que se mueve el chicle. 
6.5. Yerba usada para que el chicle no se derrame.

6.6. Trozo de chicle ya cocido con un peso aproximado de diez kilos.

6.7. Rectángulo de madera donde se echa el chicle ya cocido.

7. TRANSPORTE

7.1. Conjunto de mulas, cinco de carga y una de silla.

7.2. Conjunto de treinta mulas aproximadamente.

7.3. Persona que jala la yegua que va al frente del patacho.

7.4. Mantas con que se cubren las mercancías que llevan las arrias

7.5. Tiempo que se hace de la central hasta el primer paraje, luego de éste al siguiente y así sucesivamente.

\section{APÉNDICE 3}

INFORMANTES

1. Isidro Quiterio. 54 años. Chiclero durante 12 años.

2. Otilio Rosado. 81 años. Chiclero durante 15 años

3. Hipólito Martínez. 79 años. Chiclero durante 7 años.

4. Emilio Rivas. 37 años. Chiclero durante 14 años.

5. Marcelino Kau. 36 años. Chiclero durante 20 años.

6. Marciano Dzul. 27 años. Chiclero durante 11 años.

7. Fidel del Ángel. 58 años. Chiclero durante 16 años.

8. Ramón Hernández. 78 años. Chiclero durante 15 años.

9. Rogelio Forbes. 60 años. Chiclero durante 7 años.

10. Ponciano Argüelles. 82 años. Chiclero durante 28 años.

11. Gabriel Córdoba. 70 años. Arriero durante 24 años.

12. José Cáceres. 76 años. Chiclero durante 23 años.

13. Francisco Cordero. 83 años. Chiclero durante 30 años. 